\title{
STRATEGI MENINGKATKAN KOMITMEN PENERAPAN KESEHATAN DAN KESELAMATAN KERJA DI RUMAH SAKIT X TAHUN 2017
}

\author{
Imam Firmansyah ${ }^{1}$, Depi Yulyanti², dan RN Bayu Sela Priyatna ${ }^{3}$ \\ Sekolah Tinggi Ilmu Kesehatan (STIKes) Indramayu \\ E-mail : depi.yulyanti@gmail.com
}

\begin{abstract}
Abstrak
Penerapan Kesehatan dan Keselamatan Kerja Rumah Sakit belum menjadi prioritas pihak manajemen, hal tersebut terjadi bukan karena tidak ada regulasi dari pemerintah namun dikarenakan masih rendahnya komitmen manajemen rumah sakit untuk menerapkan K3RS. Fenomena yang terjadi di setiap rumah sakit yaitu lebih kepada pemenuhan sarana dan prasarana yang ada dalam standar akreditasi JCI 4 yang tercantum dalam standar manajemen fasilitas dan keselamatan. Hal tersebut berdampak kepada kebijakan direktur terkait dengan pelaksanaan K3RS. Pengelola K3RS digabung dengan bidang IPSRS, IPSRS dengan K3RS merupakan dua hal yang berbeda pengelolaannya sehingga penggabungan tersebut membuat program K3RS tidak berjalan. Tujuan penelitian untuk menentukan Strategi Meningkatkan Komitmen Penerapan Kesehatan dan Keselamatan Kerja Di Rumah Sakit X Tahun 2017 Menggunakan metode kualitatif, informan kepala instalasi sanitasi dan K3RS, koordinator sanitasi dan lingkungan, ketua PK3RS, sekertaris PK3RS, karyawan yang tidak masuk struktural, pasien, fungsional pengawas ketenagakerjaan madya, dan kepala dinas kesehatan, penentuan strategi dengan cara analisis SWOT. Hasil dari penelitian diketahui kekuatan utama RS X adalah sarana dan prasarana K3RS, dengan nilai sebesar 0,28. Kelemahan utama adalah kurangnya sumber daya manusia K3RS, dengan nilai sebesar 0,108. Peluang utama adalah pengawasan dari perwakilan balai K3 Provinsi Jawa Barat, dengan nilai sebesar 0,45 sedangkan ancaman utama adalah teguran dan sanksi dari pemerintah dengan nilai sebesar 0,45 . Sehingga strategi yang didapat yaitu meningkatkan pembinaan sumber daya manusia serta pemeliharaan terhadap sarana dan prasarana. Disarankan kepada Rumah Sakit agar komitmen penerapan K3RS meningkat maka program K3RS disusun berdasarkan strategi yang sudah dianalisis menggunakan SWOT.
\end{abstract}

Kata Kunci $\quad$ Kebijakan, Komitmen, K3RS, SWOT.

\section{INCREASE THE STRATEGY COMMITMENT IMPLEMENTATION OF OCCUPATIONAL HEALTH AND SAFETY IN HOSPITAL X 2017}

\begin{abstract}
The application of Occupational Health And Safety in hospital has not yet priority management, this occurred not having no regulations from the government but because the limited commitment management hospital to apply K3RS. The phenomenon happened in every hospital more to infrastructure and that is in a standard accreditation JCI 4 on standard facilities and safety management. This impact the policy director related to the implementation of K3RS. K3RS management combined with IPSRS sector, IPSRS with K3RS are two different things that the funds merger of programming K3RS did not work. Research purposes to determine increase the strategy commitment the application of occupational health and safety in the hospital X Cirebon City 2017 in a qualitative method, informants are head of installation sanitation and K3RS, coordinator of sanitation and environment, head of PK3RS, secretary of PK3RS, employees who are not included structural, patients, functional supervisory employment madya, and head of department of health, the determination of strategy by means of SWOT analysis. The result of research known the main strength of hospital $X$ is facilities $K 3 R S$, with value of 0,28. Key weakness is the lack of human resources K3RS, with value of 0,108. Opportunities major is supervision of representatives K3 West Java, with value of 0.45 while major is a threat and sanctions from the government under value of 0.45. So that strategy obtained the improvement of human resources development and maintenance over facilities and infrastructure. Suggested to hospitals commitment to the application of K3RS up and K3RS program arranged based on the already analyzed using SWOT
\end{abstract}

Keywords

: Policy, Commitment, K3RS, SWOT. 


\section{Pendahuluan}

"Rumah Sakit X (RS X) meraih sertifikat akreditasi versi 2012 tingkat paripurna (bintang lima) pada awal tahun 2016. Sertifikat yang diperoleh dari lembaga Komite Akreditasi Rumah Sakit (KARS) dalam sekali penilaian itu, berlaku dari 15 Desember 2015 s.d 14 Desember 2018".(KARS,2017)

RS X telah ditetapkan sebagai Rumah Sakit Kelas B Pendidikan Utama berdasarkan Surat Keputusan (SK) Menteri Kesehatan R.I. Nomor: 219/MENKES/SK/VI/2013 tentang penetapan sebagai Rumah Sakit Pendidikan Utama. RS X kini tengah meretas jalan untuk mewujudkan mimpi menjadi RS Kelas A yang menjadi rujukan regional Jawa Barat bagian timur. (Profil RS,2016)

Dalam usaha mewujukannya, RS X membentuk instalasi sanitasi dan K3RS guna meningkatkan mutu pelayanan dalam hal kesehatan dan keselamatan. Akan tetapi pada tahun 2015, dikeluarkan SK Panitia Kesehatan dan Keselamatan Kerja Rumah Sakit (PK3RS) dengan komposisi Sumber Daya Manusia (SDM) yang sama dengan SDM instalasi sanitasi dan K3RS di rumah sakit. Upaya penerapan K3RS sendiri telah dilaksanakan dari tahun 2010 dengan dikeluarkannya SK Direktur.

Mengingat RS X mendapat sertifikat akreditasi versi 2012 tingkat paripurna. Setiap kebijakan harus didasari komitmen dari manajemen, agar tujuan dari kebijakan tersebut dapat tercapai. Namun masih rendahnya komitmen dari manajemen terkait penetapan organisasi dan sumber daya manusia K3RS, sehingga berdampak pada penurunan kinerja karyawan, loyalitas karyawan serta berdampak juga terhadap kualitas mutu pelayanan rumah sakit dalam hal kesehatan dan keselamatan yang dapat mempengaruhi kepuasan pasien.

Upaya agar hal tersebut tidak terjadi, maka komitmen dalam penerapan K3RS harus ditingkatkan sehingga kualitas mutu pelayanan dan kepuasan pasien tetap terjaga. Hasil penelitian Yulyanti diketahui bahwa pelaksanaan manajemen K3RS bepengaruh terhadap kepuasan pasien dan karyawan rumah sakit”. (Yulyanti, 2015 \& 2016)
Melihat fenomena tersebut, setiap rumah sakit harus mampu membuat suatu strategi untuk meningkatkan komitmen terhadap penerapan K3. Namun usaha tersebut bukan upaya yang mudah dikarenakan rumah sakit harus memiliki strategi dalam mencapai keunggulan kompetitif.

Analisis Strengths, Weaknesses, Opportunities, Threats adalah suatu alat perencanaan dari suatu proses yang dapat mendorong untuk mengamati dan melihat secara kritis dalam mengidentifikasi area pengembangan ke depan. Penentuan strategi yang tepat bagi rumah sakit dimulai dengan melihat opportunity (peluang) dan threat (ancaman) yang terkandung dalam lingkungan eksternal serta memahami strength (kekuatan) dan weakness (kelemahan) pada aspek internal rumah sakit. Dengan demikian, rumah sakit mampu mencapai tujuan secara efektif dan efisien dalam menerapkannya. (Rangkuti,2016)

Selain itu, dengan menggunakan alat ukur ini secara sinergis akan menghasilkan kecepatan dan kemudahan pemantauan untuk mengendalikan jalannya suatu perencanaan. Berdasarkan uraian permasalahan tersebut, penulis melakukan penelitian dengan judul "Strategi Meningkatkan Komitmen Penerapan K3 di Rumah Sakit X Tahun 2017'.

\section{Metode Penelitian}

Penelitian ini menggunakan metode penelitian kualitatif, Informan terdiri dari informan utama dan triangulasi dengan kriteria inklusi sebagai berikut bersedia menjadi informan, karyawan tetap RS X, masa kerja karyawan minimal 1 tahun, top manajemen rumah sakit atau karyawan rumah sakit yang direkomendasikan untuk diwawancara, Pengelola Instalasi Sanitasi dan K3RS, Pengelola PK3RS, Pengawas dari Dinsosnakertrans dan Dinas Kesehatan kota Cirebon dan Pengguna Jasa Layanan. Kriteria ekslusi diantaranya Karyawan yang tidak aktif terlibat dalam pelaksanaan K3RS, Karyawan kontrak atau PTT.

Informan utama penelitian diantaranya top manajemen rumah sakit, kepala instalasi sanitasi dan K3RS, koordinator sanitasi dan 
lingkungan, ketua PK3RS, sekertaris PK3RS serta informan triangulasi diantaranya pasien, karyawan dinas kesehatan Kota Cirebon, fungsional pengawas ketenagakerjaan madya, karyawan RS X. Penelitian dilakukan di RS X Kota Cirebon pada bulan Juni s.d Juli 2017.

Penelitian dilakukan di Rumah Sakit X Kota Cirebon, Strategi disusun menggunakan analisis SWOT dan proses pengumpulan data dilakukan dengan cara wawancara mendalam dan observasi. Analisis data yang dilakukan yaitu pengaturan atau penataan data, melakukan koding dan kategorisasi, mencari pola dan proposisi penelitian, menafsirkan data, mengevaluasi penafsiran.(Saryono, 2013)

\section{Hasil Dan Pembahasan}

\section{Analisis Kekuatan Sebagai Strategi Meningkatkan Komitmen Penerapan Kesehatan Dan Keselamatan Kerja Di Rumah Sakit X}

Kekuatan yang dimiliki oleh RS X Kota Cirebon terletak pada input dan proses diantaranya sarana dan prasarana sesuai K3, ketersediaan SK, pembentukan tim dan panitia, adanya sosialisasi dan simulasi internal, pengajuan perbaikan, pendanaan, kebijakan pelaksanaan K3RS, komitmen RS, pelaksanaan sesuai SOP, penyebaran informasi, teguran langsung, area pengerjaan sesuai K3, membuat perencanaan, pelatihan, pelaporan dan adanya pemeriksaan setiap ruangan, kesadaran penggunaan APD, adanya prosedur pelaporan, jaminan dari rumah sakit dan membuang sampah medis sesuai prosedur serta beberapa standar yang terpenuhi diantaranya melakukan pemeriksaan kesehatan khusus, melaksanakan pendidikan dan penyuluhan atau pelatihan tentang kesehatan kerja dan memberikan bantuan kepada SDM rumah sakit dalam penyesuaian diri baik fisik maupun mental, meningkatkan kesehatan badan, kondisi mental (rohani) dan kemampuan fisik SDM rumah sakit, memberikan pengobatan dan perawatan serta rehabilitasi bagi SDM rumah sakit yang menderita sakit, melakukan koordinasi dengan tim panitia pencegahan dan pengendalian infeksi mengenai penularan infeksi terhadap SDM rumah sakit dan pasien, membuat evaluasi, pencatatan dan pelaporan kegiatan K3RS yang disampaikan kepada direktur rumah sakit dan unit teknis terkait di wilayah kerja rumah sakit.

Faktor yang menjadi kekuatan utama RS X Kota Cirebon adalah sarana dan prasarana K3RS, dengan nilai tertinggi sebesar 0,28 adapun hasil wawancara dengan informan adalah sebagai berikut :

"Nah kalau sarana dan prasarana $\mathrm{K} 3$, yang pertama itu tentang terutama untuk pengendalian pencegahan kebakaran itu ada alur evakuasi, ada tangga darurat, ada helm red code, ada papan red code itu, ada deteksi panas sama deteksi asap. Itu sarana dan pra sarana untuk menambah, untuk pengendalian atau pengolaan B3 ada spill kit, spill kit terus ada lemari khusus $B 3$, penyimpanan $B 3$, terus ada tempat penyimpanan atau TPS B3 untuk B3nya. Kalau untuk parameter penyehatan lingkungan juga ada sarana yang seperti alat kebisingan, pencahayaan, suhu kelembaban itu".

Perlu diketahui bahwa salah satu aspek penilaian akreditasi rumah sakit oleh lembaga KARS adalah sarana dan prasarana rumah sakit yang tertuang dalam standar manajemen fasilitas dan keselamatan. Sehingga sarana prasarana menjadi prioritas manajemen untuk menjaga mutu pelayanan rumah sakit.

Pemenuhan Sarana dan prasarana di RS $\mathrm{X}$ dialokasikan untuk standar pelayananan K3RS, standar teknis sarana dan prasarana. Bukan hanya pemenuhan pada sarana prasarana pencegahan dan penanggulangan kebakaran saja melainkan juga beberapa sarana lainnya untuk menjamin lingkungan kerja yang aman, sehat dan selamat sehingga dapat meningkatkan kinerja karyawan rumah sakit.

Hartono, D (2014) menyatakan bahwa sarana prasarana dan lingkungan kerja berpengaruh signifikan positif terhadap kinerja pegawai secara parsial, variabel sarana prasarana dan lingkungan kerja berpengaruh positif signifikan terhadap kinerja pegawai secara bersamasama. Untuk itu dibutuhkan pembinaan serta pemeliharaan terhadap sarana dan prasarana K3RS agar tidak terkendala dalam penggunaannya. 


\section{Analisis Kelemahan Sebagai Strategi Meningkatkan Komitmen Penerapan Kesehatan Dan Keselamatan Kerja Di Rumah Sakit X}

Kelemahan yang dimiliki oleh RS X terletak pada input dan proses diantaranya tidak mempunyai ahli K3RS, penggabungan organisasi, perencanaan dan penganggaran, rangkap jabatan, profesionalitas karyawan yang tidak sesuai, penggabungan anggaran, proses pengajuan unit yang lama, tertusuk jarum, tidak ada transparansi anggaran, bentuk organisasi K3RS, kurangnya SDM K3RS, kurangnya kesadaran karyawan terkait penerapan K3RS, kunjungan hanya 1 bulan sekali dan penyimpanan limbah medis yang tidak benar serta beberapa standar yang belum terpenuhi diantaranya tidak melakukan pemeriksaan kesehatan sebelum bekerja, tidak ada pemeriksaan kesehatan berkala bagi SDM rumah sakit, tidak ada pemberian imunisasi bagi SDM rumah sakit, tidak melaksanakan kegiatan surveilans kesehatan kerja, tidak melaksanakan pemantauan lingkungan kerja dan ergonomi yang berkaitan dengan kesehatan kerja (pemantauan atau pengukuran terhadap faktor fisik, kimia, biologi, psikososial dan ergonomi).

Kelemahan utama adalah kurangnya sumber daya manusia K3RS dengan nilai tertimbang sebesar 0,108, adapun hasil wawancara dengan informan adalah sebagai berikut :

"Faktor yang menghambat, satu dari karyawan eh dari organisasi $\mathrm{K} 3$ sendiri kita SDM kita kurang, untuk 1800 personil K3 harusnya banyak 1400 malah ya nambah lagi, harusnya punya personal xxxx dan xxx tapi ternyata kita sangat kurang dari itu, salah satu dan paling penting untuk hambatan dari kita sendiri dari SDM kita sendiri.."

Sunarta (2008) memaparkan organisasi yang tidak didukung pegawai atau karyawan yang sesuai baik dari aspek kuantitas, kualitas, strategi, dan operasional yang baik, maka dapat dipastikan organisasi tersebut akan sulit mempertahankan dan mengembangkan eksistensinya dimasa yang akan datang.

Menurut Rohana, S (2016) perencanaan sumber daya manusia memberikan perkiraan tentang jumlah dan jenis karyawan yang diperlukan suatu organisasi untuk mencapai tujuan organisasi. Jumlah dan jenis karyawan yang dibutuhkan mempunyai pengaruh yang besar tujuan perencanaan SDM pada sebuah organisasi.

Rumah sakit harus mampu mengantisipasi dan menyesuaikan dengan perubahan regulasi yang terjadi dengan standar pelayanan dan mutu pelayanan. Upaya perencanaan SDM akan menjadi lebih penting bagi rumah sakit karena evaluasi kegiatan dan proses restrukturisasi organisasi selalu membayangi kehidupan organisasi. Permasalahan terkait dengan pemenuhan SDM dan tidak adanya unit ataupun instalasi yang menangani K3RS menjadi permasalahan yang sama di Rumah Sakit Negeri yang ada di Indramayu.(Yulyanti, 2015)

Untuk itu, diharuskan RS X Kota Cirebon segera menambah sumber daya manusia K3RS. Dalam perekrutannya dikhusukan untuk SDM yang berorientasi di K3RS. Langkah ini bertujuan meningkatkan efektivitas dalam pembinaan dan pemeliharaan terhadap sarana dan prasarana K3RS.

\section{Analisis Peluang Sebagai Strategi Meningkatkan Komitmen Penerapan Kesehatan Dan Keselamatan Kerja Di Rumah Sakit X}

Peluang yang dimiliki oleh RS X terletak pada input dan proses diantaranya kerjasama pencegahan kebakaran, pelatihan eksternal, kewajiban melapor ke dinas kesehatan, pengawasan dari perwakilan balai K3 Provinsi Jawa Barat dengan cakupan tugas wilayah 3 Cirebon.

Faktor yang menjadi peluang utama RS $\mathrm{X}$ adalah pembinaan dan pengawasan dari dinas kesehatan perwakilan balai K3 Provinsi Jawa Barat terkait sarana dan prasarana K3RS, dengan nilai tertimbang tertinggi sebesar 0,45, adapun hasil wawancara dengan informan adalah sebagai berikut :

“...kita juga mempunyai kewajiban untuk membina rumah sakit”

Secara struktur organisasi, berdasarkan keputusan menteri kesehatan no. 1087 tentang standar K3RS dinyatakan bahwa dinas kesehatan sehingga dinas kesehatan 
berkewajiban untuk membina rumah sakit K3RS dan rumah sakit berkewajiban untuk melaporkan kegiatan-kegiatan program K3RS yang dilaksanakan ke Dinas Kesehatan.

Sami'an dan Aprilian, E (2013) menyatakan bahwa kepemimpinan dan pengawasan secara bersama-sama berpengaruh positif terhadap kinerja karyawan. Kinerja K3RS harus lebih dibina serta diawasi secara konsisten demi terwujudnya budaya K3 di lingkungan rumah sakit. Ada banyak aspek yang harus dibina dan diawasi dalam implementasinya seperti komitmen rumah sakit tersebut dalam perencanaan SDM, anggaran dan materil yang meliputi sarana prasarana K3RS dan lainnya. Optimalnya pengawasan itu bertujuan agar K3 bisa dilaksanakan dengan baik dan sesuai peraturan yang ada.

Diharapkan kepada RS X Kota Cirebon agar segera berkoordinasi dengan dinas kesehatan Kota Cirebon dan perwakilan balai K3 Provinsi Jawa Barat. Langkah ini adalah upaya melakukan pembinaan serta pengawasan secara konsisten agar sarana dan prasarana K3RS tetap terjaga fungsinya.

\section{Analisis Ancaman Sebagai Strategi Meningkatkan Komitmen Penerapan Kesehatan Dan Keselamatan Kerja Di Rumah Sakit X}

Ancaman yang dihadapi oleh RS X Kota Cirebon terletak pada input dan proses diantaranya kurang patuh terhadap penggunaan APD, belum ada sosialisasi dari pemerintah, mengabaikan peraturan K3RS, terbebani oleh aturan pengurus K3RS dan belum ada laporan tertulis.

Ancaman utama adalah belum ada sosialisasi dari pemerintah dengan nilai tertimbang terbesar sebesar 0,45 , adapun hasil wawancara dengan informan adalah sebagai berikut :

“...sosialisasi dari pemerintah daerahnya belum rasanya”.

Pratasis (2011) menyatakan faktor penghambat penting yang paling berpengaruh dalam implementasi K3 di Propinsi Sulawesi Utara adalah faktor perencanan anggaran, kemudian diikuti oleh pengawasan dan sanksi, frekuensi sosialisasi dari pemerintah, budaya pekerja dilapangan, sedangkan perencanaan strategis dan prioritas perusahaan, tingkat kerumitan desain proyek, dan faktor ketersediaan peralatan K3 adalah faktor-faktor penghambat yang pengaruhnya lemah dalam penerapan K3.

Pemerintah daerah dan pusat memiliki peran penting dalam sosialisasi terhadap implementasi K3 bukan hanya pada perusahaan melainkan juga pada rumah sakit. Untuk itu dibutuhkan langkah konkrit dari RS $\mathrm{X}$ untuk bersinergi dengan pemerintah dalam implementasi K3 yang khususnya pada sarana dan prasarana K3RS.

\section{Analisis Strategi Meningkatkan Komitmen Penerapan Kesehatan Dan Keselamatan Kerja Di Rumah Sakit X}

Berdasarkan metode MCUA didapat alternatif pemecahan masalah yaitu Meningkatkan Pembinaan SDM Serta Pemeliharaan Terhadap Sarana dan Prasarana K3RS Untuk Menunjang Penerapan K3 di Rumah Sakit.

Telah disusun suatu rencana strategis yang akan dijadikan pegangan dalam melakukan kegiatan selanjutnya. Kegiatan tersebut harus berorientasi terhadap peningkatan komitmen RS X.

Pada perencanaan strategis tersebut didapatkan tujuan program, indikator, asumsi dan risiko yang kemungkinan akan muncul dalam pelaksanaannya. Oleh karena itu, diharapkan ada langkah antisipatif dari RS X Kota Cirebon yang bertujuan meminimalisir risiko tersebut. Adapun langkahnya sebagai berikut rapat internal dengan panitia K3RS, audiensi dengan direktur untuk menyatakan kebijakan K3 dan dituangkan secara tertulis, pertemuan resmi dengan pegawai Dinas Kesehatan Kota Cirebon dan perwakilan Balai Pengawas K3 Provinsi Jawa Barat serta memberikan pemaparan terkait profil K3RS dan capaian program serta sarana prasarana K3RS yang sudah ada di RS X, mensosialisakan kebijakan yang telah dibuat oleh direktur kepada seluruh karyawan untuk dilaksanakan dengan baik, dan Dinas Kesehatan Kota Cirebon serta dinas ketenagakerjaan memberikan pembinaan 
kepada seluruh karyawan tentang pentingnya penerapan budaya K3 ditempat kerja.

\section{Penutup}

Berdasarkan penelitian yang telah dilakukan menggunakan metode SWOT diketahui strategi yang dapat diterapkan untuk meningkatkan komitmen dalam penerapan K3RS di RS X yaitu meningkatkan pembinaan SDM serta pemeliharaan terhadap sarana dan prasarana K3RS untuk menunjang penerapan K3 di Rumah Sakit. Langkah yang ditempuh meliputi : Rapat internal dengan panitia K3RS, audiensi dengan direktur untuk menyatakan kebijakan K3 dan dituangkan secara tertulis, melakukan pertemuan resmi dengan pegawai Dinas Kesehatan Kota Cirebon dan perwakilan Balai Pengawas K3 Provinsi Jawa Barat untuk mebicarakan pembinaan terhadap karyawan agar memiliki komitmen yang sama dalam penerapan K3RS Memberikan pemaparan terkait profil K3RS dan capaian program serta sarana prasarana K3RS yang sudah ada di RS X kepada Dinas Kesehatan Kota Cirebon dan perwakilan Balai Pengawas K3 Provinsi Jawa Barat, mensosialisakan kebijakan yang telah dibuat oleh direktur kepada seluruh karyawan untuk dilaksanakan dengan baik, pembinaan dari Dinas Kesehatan Kota Cirebon serta dinas ketenagakerjaan kepada seluruh karyawan tentang pentingnya penerapan budaya K3 ditempat kerja.

\section{Daftar Pustaka}

Hartono, D. 2014. "Pengaruh Sarana Prasarana dan Lingkungan Kerja Terhadap Kinerja Pegawai Dinas Pendidikan Kota Banjarbaru. Vol 10, No 2, April-Juni 2014". Dari https://sia.stiepancasetia.ac.id/do wnload-jurnal.php?id=103. (Diakses pada tanggal 24 Juli 2017, Pukul 06.00 WIB).

KARS.or.id/ (Diakses : http : // akreditasi. kars. or. id/ accreditation/ report/ report_accredited. php di Indramayu pada tanggal 27 Februari 2017).
Kesehatan, Menteri. Keputusan Menteri Kesehatan Republik Indonesia no. 1087/menkes. SK/VIII/2010. Tentang Standar Kesehatan Dan Keselamatan Kerja Di Rumah Sakit. Jakarta. 2010.

Pratasis P. 2011."Strategi Peningkatan Implementasi Keselamatan Dan Kesehatan Kerja Pada Perusahaan Jasa Konstruksi Di Propinsi Sulawesi Utara". Vol 9. Dari https://ejournal.unsrat.ac.id/index .php/tekno/article/view/3937.

(Diakses pada tanggal 24 Juli 2017, Pukul 06.20 WIB).

Profil RS X Kota Cirebon, Tahun 2016. Rangkuti, F. 2016. Analisis SWOT Teknik Membedah Kasus Bisnis. Jakarta: PT. Gramedia Pustaka Utama.

Rohana, S, Wulandari, C, Yuwono, S. B. 2016. "Peningkatan Kualitas Dan Kuantitas Sumberdaya Manusia Pada Kesatuan Pengelolaan Hutan Lindung (KPHL) Batutegi Dan Kota Agung Utara Di Provinsi Lampung". Vol 4, No 1, Januari 2016.

Dari digilib.unila.ac.id/12250.

(Diakses pada tanggal 24 Juli 2017, Pukul 06.15 WIB).

Rohana, S, Wulandari, C, Yuwono, S. B. 2016. "Peningkatan Kualitas Dan Kuantitas Sumberdaya Manusia Pada Kesatuan Pengelolaan Hutan Lindung (KPHL) Batutegi Dan Kota Agung Utara Di Provinsi Lampung". Vol 4, No 1, Januari 2016. Dari

digilib.unila.ac.id/12250.

(Diakses pada tanggal 24 Juli 2017, Pukul 06.15 WIB).

Sami' an dan Aprilian, E. 2013. "Pengaruh Kepemimpinan Dan Pengawasan Terhadap Kinerja Karyawan PT Kereta Api Indonesia (Persero) Di Kantor Daop IV Semarang". Vol 23, No $1 . \quad$ Dari journals.ums.ac.id/index.php/jpis/ 
article/download/836/558.

(Diakses pada tanggal 24 Juli

2017, Pukul 06.25 WIB).

Saryono dan Anggraeni. 2013.

Metodologi Penelitian Kualitatif

dan Kuantitatif dalam Bidang

Kesehatan. Yogyakarta: Nuha Medika.

Sunarta. 2008. "Perencanaan Sumber Daya Manusia”. Vol 4, No 1. Dari https://journal.uny.ac.id/index.ph p/jmp/article/view/3710/3183.

(Diakses pada tanggal 24 Juli 2017, Pukul 06.30 WIB).

Surat Keputusan Menteri Kesehatan Republik Indonesia Nomor: 219/MENKES/SK/VI/2013 tentang penetapan sebagai Rumah Sakit Pendidikan Utama. 2013.

Yulyanti, Depi, Hanifa Maher Denny, and Sudiro Sudiro. "Evaluasi Manajemen Kesehatan Dan Keselamatan Kerja Rumah Sakit (Studi Aspek Manajemen K3RS di RSUD Indramayu Tahun 2015." PhD diss., UNIVERSITAS DIPONEGORO, 2015.

Yulyanti, Depi. Pengaruh Pelaksanaan Manajemen K3RS Terhadap Kepuasan Pasien Rumah Sakit X. Jurnal Kesehatan Indra Husada, Volume 3 No.2. 2015.

Yulyanti, Depi. Pengaruh Pelaksanaan Manajemen K3RS Terhadap Kepuasan Karyawan Rumah Sakit $X$ di Kabupaten Indramayu. Prosiding Seminar Nasional Dan Diseminasi Penelitian Kesehatan. STIKes Bhakti Tunas Husada. 2016. 